American Medical Journal 1 (1): 8-22, 2010

ISSN 1949-0070

(C) 2010 Science Publications

\title{
Randomized Clinical Stroke Trials In 2008
}

\author{
Meheroz H. Rabadi \\ Veterans Affairs Medical Center at Oklahoma University, \\ 921 NE 13th Street, Oklahoma City OK, US
}

\begin{abstract}
Problem statement: Stroke ranks as the third leading cause of death and the leading cause of serious, long-term disability; estimated direct and indirect cost of stroke for 2009 was $\$ 68.9$ billion. Approach: The objective of this review was to examine the effectiveness of emerging pharmacotherapies in patients with acute ( $\leq 2$ weeks), sub-acute (2-12 weeks) and chronic $(\geq 12$ weeks) stroke studied in Randomized Control Trials (RCT's) published in 2008. Medline search was performed to identify all RCT's in acute, sub-acute and chronic stroke treatment in the year 2008. The search strategy used for PubMed included key words such as Randomized Controlled Trials (RCT), Stroke OR cerebrovascular disorders OR CVA, Ischemic stroke OR ischemia, Hemorrhage OR intraparenchymal hemorrhage OR subarachnoid hemorrhage, Thrombolytics OR tissue plasminogen activator OR alteplase OR t-PA, Diabetes mellitus OR hyperglycaemia, Hypertension OR raised blood pressure, Aspirin OR anti-platelets, Warfarin OR anticoagulant, Antidepressants, Neuroprotectants and Coiling OR stents OR endovascular. Search limits included Human, Adult (age $>19$ years), English language and Publication date: 1/1/2008 to 12/31/2008. Results: Eleven categories of 21 RCT's were found and analyzed. Conclusion/Recommendations: There is sufficient evidence to suggest that: (1) extending the time-window for administration of alteplase from 3-4.5 h after stroke onset does improve clinical outcome; (2) treatment of hypertension in the elderly does reduce rate of stroke, cardiac failure and death from stroke and (3) at present there are no neuroprotectants on the horizon.
\end{abstract}

Key words: Acute stroke. pharmacotherapies, endovascular

\section{INTRODUCTION}

This review focuses on the clinical usefulness of commonly used pharmacological agents, readily available to clinicians caring for stroke patients that were assessed in clinical trials published in 2008 .

Acute stroke therapies:

Title: Emergency administration of abciximab for treatment of patients with acute ischemic stroke: Results of an international phase III trial.

Abciximab (a chimeric mouse/human monoclonal antibody with a high affinity for platelet glycoprotein $\mathrm{IIb} / \mathrm{III}$ receptor) has been found to be a safe and effective treatment of acute ischemic stroke (Abciximab in Ischemic Stroke Investigators, 2000; Abciximab Emergent Stroke Treatment Trial Investigators, 2005). This international, randomized, placebo-controlled; double-blind phase III study assessed intravenous abciximab efficacy and safety in patients with acute ischemic stroke (Adams et al., 2008). The study was comprised of a primary cohort of patients treated within $5 \mathrm{~h}$ of onset of stroke; a companion cohort of patients treated 5-6 $\mathrm{h}$ after stroke and a smaller cohort of patients treated within $3 \mathrm{~h}$ of stroke present on awakening. The primary efficacy measure was the modified Rankin Scale (mRS) score at 3 months adjusted to the baseline severity of stroke among subjects in the primary cohort. The primary safety outcome was the rate of symptomatic or fatal intracranial hemorrhage within 5 days of stroke. The trial was planned to enroll 1800 patients but was terminated prematurely after having enrolled 808 patients in all cohorts on the recommendation of an independent safety and efficacy monitoring board due to an unfavorable benefit-risk profile of abciximab. At 3 months, $33 \%$ of patients assigned to placebo (72/218) and $32 \%$ of patients assigned to abciximab $(71 / 221 ; \mathrm{p}=0.944)$ in the primary cohort had a favorable treatment response on mRS. Within 5 days of enrollment, approximately $5.5 \%$ of abciximab-treated and $0.5 \%$ of placebo-treated patients in the primary cohort had symptomatic or fatal intracranial hemorrhage $(p=0.002)$. The trial did not show improvement in the primary outcome measure with abciximab among patients in the companion and wake-up cohorts. In conclusion this trial showed that intravenous abciximab for the treatment of patients with acute ischemic stroke was neither efficacious nor safe with an increased rate of symptomatic or fatal 
intracranial hemorrhage in the primary and wake-up cohorts (13.6\% versus $5 \%$ for placebo).

Intravenous thrombolysis with alteplase is the only FDA approved treatment for acute ischemic stroke, but its efficacy and safety when administered more than $3 \mathrm{~h}$ after the onset of symptoms have not been established. Two studies tested the efficacy and safety of alteplase administered 3-6 h after the onset of an ischemic stroke (Davis et al., 2008; Hacke et al., 2008).

Title: Effects of alteplase beyond $3 \mathrm{~h}$ after stroke in the Echoplanar Imaging Thrombolytic Evaluation Trial (EPITHET): A placebo-controlled randomized trial.

This trial tested the effectiveness of intravenous tissue plasminogen activator (alteplase) in promoting reperfusion and attenuating infarct growth when administered 3-6 $\mathrm{h}$ after ischemic stroke onset to patients with mismatch on Perfusion-Weighted (PWI) and Diffusion-Weighted (DWI) MRI. In this prospective randomized trial, patients either received alteplase $(n=52)$ or placebo $(n=49) 3-6 h$ after onset of ischemic stroke (Davis et al., 2008). PWI and DWI were carried out before and 3-5 days after therapy, with T2-weighted MRI at 90 days. The primary endpoint was infarct growth between baseline DWI and day 90 T2 lesion in mismatch patients. Major secondary endpoints were reperfusion, good neurological outcome (measured by National Institute of Health Stroke Scale (NIHSS)) and good functional outcome (measured by modified Rankin Score (mRS)). Mean age was 71.6 years and median score on the NIHSS was 13 . Mismatch on PWI and DWI was in 85 of $99(86 \%)$ patients. The mean infarct growth (an exponential of the mean log of relative growth) was 1.24 with alteplase and 1.78 with placebo (ratio 0.69 , 95\% CI 0.38-1.28; Student's t-test $\mathrm{p}=0.239$ ); the median relative infarct growth was 1.18 with alteplase and 1.79 with placebo (ratio 0.66, 0.36-0.92; Wilcoxon's test $\mathrm{p}=0.054$ ). Reperfusion was commonly seen with alteplase than with placebo and was associated with less infarct growth $(\mathrm{p}=0.001)$, better neurological outcome $(\mathrm{p}<0.0001)$ and better functional outcome $(\mathrm{p}=0.010)$. This study showed alteplase increased reperfusion in patients who had mismatch, but did not lower infarct growth size. Because of reperfusion, there were improved neurological and functional outcomes. This trial highlights the need for more phase III studies beyond $3 \mathrm{~h}$ after onset of acute ischemic stroke.

Title: Thrombolysis with alteplase 3-4.5 h after acute ischemic stroke.

Eight hundred and twenty one patients with ischemic stroke were randomly assigned to the alteplase
( $\mathrm{n}=418,0.9 \mathrm{mg} \mathrm{kg}^{-1}$ of body weight) or to the placebo $(\mathrm{n}=403)$ group (Hacke et al., 2008). The median time for the administration of alteplase was $3 \mathrm{~h} 59 \mathrm{~min}$. The primary end point was disability at 90 days, dichotomized as a favorable outcome (a score of 0 or 1 on the modified Rankin Scale (mRS), which has a range of $0-6$, with 0 indicating no symptoms at all and 6 indicating death) or an unfavorable outcome (a score of 2-6 on the $\mathrm{mRS}$ ). The secondary end point was a global outcome analysis of 4 neurologic and disability scores combined. Safety end points included death, symptomatic intracranial hemorrhage and other serious adverse events. More patients had a favorable outcome with alteplase than with placebo (52.4 Vs $45.2 \%$; odds ratio, $1.34 ; 95 \%$ Confidence Interval (CI), 1.02 to 1.76 ; $\mathrm{p}=0.04)$ on the $\mathrm{mRS}$ for a score of 0 or 1 . In the global analysis, outcome also improved with alteplase compared with placebo (odds ratio, 1.28; 95\% CI, 1.00$1.65 ; \mathrm{p}<0.05)$. The incidence of intracranial hemorrhage was higher with alteplase than with placebo (for any intracranial hemorrhage, $27.0 \mathrm{Vs} 17.6 \%$; $\mathrm{p}=0.001$; for symptomatic intracranial hemorrhage, $2.4 \mathrm{Vs} 0.2 \%$; $\mathrm{p}=0.008)$. Mortality did not differ between the groups (7.7 and $8.4 \%$, respectively; $\mathrm{p}=0.68$ ), nor the rate of other serious adverse events. In conclusion, intravenous alteplase administered between 3 and $4.5 \mathrm{~h}$ after the onset of symptoms significantly improved clinical outcomes in patients with acute ischemic stroke; however; alteplase was more frequently associated with symptomatic intracranial hemorrhage.

The recanalisation rate of thrombolysis after r-TPA for acute ischemic stroke is $26 \%$ for internal carotid and $69 \%$ for middle cerebral arteries (Christou et al., 2002) Various approaches are being studied to enhance this rate of thrombolysis induced recanalisation after an acute ischemic stroke (Christou et al., 2002; Pancioli et al., 2008; Alexandrov et al., 2004).

Title: The Combined Approach to Lysis Utilizing Eptifibatide and rt-PA in Acute Ischemic Stroke: The CLEAR Stroke Trial.

Combination of a reduced-dose fibrinolytic agent and a Glycoprotein (GP) IIb/IIIa receptor antagonist has been shown to improve the rate of recanalization versus fibrinolysis alone in the treatment of myocardial infarction (Topol, 2001). This trial assessed the safety of treating acute ischemic stroke patients within $3 \mathrm{~h}$ of symptom onset with this combination of eptifibatide and t-PA (Pancioli et al., 2008). This was a multicenter, double-blind, randomized, dose-escalation and safety study. Patients were randomized 3:1 to either lowdose t-PA (tier $1=0.3 \mathrm{mg} \mathrm{kg}^{-1}$, tier $2=0.45 \mathrm{mg} \mathrm{kg}^{-1}$ ) plus eptifibatide $\left(75 \mathrm{ug} \mathrm{\textrm {kg } ^ { - 1 }}\right.$ bolus followed by 
$0.75 \mathrm{ug} \mathrm{kg}^{-1} \mathrm{~min}^{-1}$ infusion over $2 \mathrm{~h}$ ) or standard-dose tPA $\left(0.9 \mathrm{mg} \mathrm{kg}^{-1}\right)$. The primary safety end point was the incidence of symptomatic intra-cerebral hemorrhage within 36 h. A secondary analysis was its clinical efficacy. Ninety-four patients (40 in tier 1 and 54 in tier 2 ) were enrolled. The combination group of the 2 dose tiers $(n=69)$ had a median age of 71 years and a median baseline National Institutes of Health Stroke Scale (NIHSS) score of 14, while the standard-dose tPA group $(n=25)$ had a median age of 61 years and a median baseline NIHSS score of 10 ( $\mathrm{p}=0.01$ for NIHSS score). Fifty-two (75\%) of the combination treatment group and $24(96 \%)$ of the standard treatment group had a baseline modified Rankin scale score of 0 $(\mathrm{p}=0.04)$. There was $1(1.4 ; 95 \%$ CI, $0-4.3 \%)$ symptomatic intracranial hemorrhage in the combination group and $2(8.0 ; 95 \% \mathrm{CI}, 0-19.2 \%)$ in the t-PA-only arm $(\mathrm{p}=0.17)$. The study was halted by the independent data safety monitoring board because on their review the safety profile of combination therapy at the tier 2 doses suggested that further enrollment was statistically unlikely to indicate inadequate safety for the combination treatment group, the ultimate outcome of the study. The study found the combination of reduced-dose t-PA plus eptifibatide to be safe in acute ischemic stroke trials. However, there was a trend toward increased clinical efficacy of standard-dose t-PA compared with the combination treatment group. The authors speculated why combination treatment was less clinically efficacious. It may have been due to the baseline characteristics of the combination group for older age (71 years) and higher baseline median NIHSS score of 14 compared to standard t-PA group. Also, the time delay from onset to administration of medication was $2.55 \mathrm{~h}$ in the combination therapy group in order to maintain the double-blind drug dosing.

Title: Sonothrombolysis with transcranial color-coded sonography and recombinant tissue-type plasminogen activator in acute middle cerebral artery main stem occlusion: Results from a randomized study.

Sonothrombolysis is a new treatment approach in patients with acute ischemic stroke. CLOTBUST was the first randomized trial to show effectiveness of sonothrombolysis as a treatment modality in acute ischemic stroke patients (Alexandrov et al., 2004). In this single-center trial, 37 subjects with acute middle cerebral artery main stem occlusion (no residual blood flow in the middle cerebral artery main stem (Thrombolysis in Brain Ischemia recanalization grade 0)) were randomized into an Ultrasound (US) group $(\mathrm{n}=19)$ receiving $1 \mathrm{~h}$ transcranial continuous insonation using a 1.8-MHz Doppler US probe or a control group $(\mathrm{n}=18)$ (Eggers et al., 2008). All of the subjects received standard thrombolysis with intravenous recombinant tissue-type Plasminogen Activator (tPA). The US group showed greater improvement in National Institutes of Health Stroke Scale scores at days 1 and 4 and a higher median Thrombolysis in Brain Ischemia grade $1 \mathrm{~h}$ after recombinant tissue-type plasminogen activator initiation compared with the control group. Recanalization (complete or partial) after $1 \mathrm{~h}$ occurred in $57.9 \%$ of the US group and $22.2 \%$ of the control group ( $\mathrm{p}=0.04)$. After 90 days, 4 subjects from the US group had a modified Rankin Score $\leq 1$ (none from the control group; $p=0.106$ ) and 8 had a barthel index $\geq 95$ (none from the control group; $\mathrm{p}=0.003$ ). Three subjects from the US group (15.8\%) and one $(5.6 \%)$ in the control group developed symptomatic intracranial hemorrhage $(\mathrm{p}=0.60)$. This small randomized study reaffirmed the beneficial effect of transcranial ultrasound on recanalization and improving short-term clinical outcomes in subjects with middle cerebral artery main stem occlusion who received tPA treatment.

Title: A pilot randomized clinical safety study of sonothrombolysis augmentation with ultrasoundactivated perflutren-lipid microspheres for acute ischemic stroke.

The investigators of this study, after having previously shown sonothrombolysis to be an effective alternative treatment modality for acute stroke patients (Alexandrov et al., 2004); tested whether Ultrasound (US) activated perflutren-lipid microspheres $(\mu S)$ induced recanalization was safe and feasible in acute stroke patients who received IV tissue Plasminogen Activator (tPA) (Alexandrov et al., 2008). US is thought to transiently expand $\mu \mathrm{S}$, thereby transmitting energy momentum to surrounding fluids accelerating residual flow and causing microfragmentation of the thrombus. Patients seen within $3 \mathrm{~h}$ of their acute stroke and who had on Transcranial Doppler (TCD) an abnormal residual blood flow (Thrombolysis In Brain Ischemia (TIBI) residual flow grades $0-3$ before tPA, were randomization in a 3:1 ratio to either the Target $(\mathrm{tPA}+\mathrm{TCD}+2.8 \mathrm{~mL} \mu \mathrm{S})(\mathrm{n}=12)$ or control group $(\mathrm{tPA}+\mathrm{TCD})(\mathrm{n}=3)$. The primary safety end point was symptomatic Intracranial Hemorrhage (sICH)

with worsening by $\geq 4$ NIHSS points within $72 \mathrm{~h}$. After treatment, asymptomatic ICH occurred in 3 Target and 1 Control subjects and sICH was not seen in any study subject. $\mu \mathrm{S}$ reached MCA occlusions at velocities higher than surrounding residual red blood cell flow: $39.8 \pm 11.3$ Vs $28.8 \pm 13.8 \mathrm{~cm} \mathrm{sec}^{-1}, \mathrm{p}<0.001$. In $75 \%$ of subjects, $\mu \mathrm{S}$ permeated to areas with no pretreatment 
residual flow and in $83 \%$ residual flow velocity improved at a median of $30 \mathrm{~min}$ from start of $\mu \mathrm{S}$ infusion (range $30 \mathrm{sec}$ to $120 \mathrm{~min}$ ) by a median of $17 \mathrm{~cm} \mathrm{sec}^{-1}$ (118\% above pretreatment values). When the current study recanalization rates were compared with the tPA control arm of the CLOTBUST trial the following results were documented: Complete recanalization occurred $(50 \%$ versus $18 \%)$, partial $(33 \%$ versus $21 \%)$, none $(17 \%$ versus $49 \%), \mathrm{p}=0.028$. At $2 \mathrm{~h}$, sustained complete recanalization occurred in $42 \%$ versus $13 \%(\mathrm{p}=0.003)$ and NIHSS scores $0-3$ were reached by $17 \%$ versus $8 \%(p=0.456)$. In this study perflutren $\mu \mathrm{S}$ reached beyond intracranial occlusion and achieved a higher recanalization rate with no increase in sICH after systemic thrombolysis. The main limitations of this study were the small numbers of patients enrolled and only those centers participated who had expertise in the use of sonothrombolysis with trained personal that could operate the TCD machine.

Stroke and hypertension: Long-term antihypertensive therapy has been shown to reduce the risk of stroke (10) and stroke recurrences.

Title: Treatment of hypertension in patients 80 years of age or older.

This study assessed whether the treatment of patients with hypertension who are 80 years of age or older is beneficial. In this multi-center, international trial of 3845 patients who were 80 years of age or older and had a sustained systolic blood pressure of $160 \mathrm{~mm}$ $\mathrm{Hg}$ or more, were randomly assigned to receive either the diuretic indapamide (sustained release, $1.5 \mathrm{mg}$ ) or matching placebo (Alexandrov et al., 2008). The angiotensin-converting-enzyme inhibitor perindopril (2 or $4 \mathrm{mg}$ ), or matching placebo, was added if necessary to achieve the target blood pressure of $150 / 80 \mathrm{~mm} \mathrm{Hg}$. The primary end point was fatal or nonfatal stroke. There were 1933 patients in the active-treatment group and 1912 patients in the placebo group. The groups were matched for: (a) mean age, 83.6 years, (b) mean blood pressure while sitting, 173.0/90.8 $\mathrm{mm} \mathrm{Hg}$ and (c) $11.8 \%$ with a history of cardiovascular disease. The median follow-up was 1.8 years. At 2 years, the mean blood pressure, while sitting, was 15.0/6.1 $\mathrm{mm} \mathrm{Hg}$ lower in the active-treatment than in the placebo group. In an intention-to-treat analysis, active treatment was associated with a $30 \%$ reduction in the rate of fatal or nonfatal stroke (95\% Confidence Interval (CI), -1 to 51; $\mathrm{p}=0.06)$, a $39 \%$ reduction in the rate of death from stroke $(95 \% \mathrm{CI}, 1-62 ; \mathrm{p}=0.05)$, a $21 \%$ reduction in the rate of death from any cause $(95 \% \mathrm{CI}, 4-35 ; \mathrm{p}=0.02)$, a
$23 \%$ reduction in the rate of death from cardiovascular causes $(95 \% \mathrm{CI},-1$ to $40 ; \mathrm{p}=0.06$ ) and a $64 \%$ reduction in the rate of heart failure $(95 \% \mathrm{CI}, 42-78$; $\mathrm{p}<0.001)$. Fewer serious adverse events were reported in the active-treatment group (358, Vs 448 in the placebo group; $\mathrm{p}=0.001$ ). This study provides further evidence that antihypertensive treatment with indapamide (sustained release), with or without perindopril, in persons 80 years of age or older is beneficial as a primary prevention in reducing the rate of strokes, heart failure and death from stroke and all cause mortality. This study highlights the importance of hypertension control in the elderly (>80 years and older) who represent the fastest growing segment of the population.

Title: Telmisartan to Prevent Recurrent Stroke and Cardiovascular Events. (Prevention Regimen for Effectively Avoiding Second Strokes (PRoFESS) Study Group).

Inhibition of the renin-angiotensin system in highrisk vasculopaths has been shown to reduce the rate of cardiovascular events, including stroke (Chitravas et al., 2007). In this study the effect of lowering of blood pressure was assessed using the renin-angiotensin system blocker, telmisartan, soon after a stroke. In this multicenter trial involving 20,332 patients with recent ischemic stroke, patients were randomized to receive telmisartan (80 mg daily) $(\mathrm{n}=10,146)$ or placebo ( $\mathrm{n}=10,186$ ) (Yusuf et al., 2008). The primary outcome was stroke recurrence. The secondary outcome was a composite of stroke recurrence, myocardial infarction or death from vascular causes or new or worsening heart failure and new-onset diabetes. The median interval from stroke to randomization was 15 days. During a mean follow-up of 2.5 years, the mean blood pressure was $3.8 / 2.0 \mathrm{~mm} \mathrm{Hg}$ lower in the telmisartan group than in the placebo group. A total of 880 patients $(8.7 \%)$ in the telmisartan group and 934 patients $(9.2 \%)$ in the placebo group had a subsequent stroke (hazard ratio in the telmisartan group, 0.95; 95\% Confidence Interval $(\mathrm{CI}), \quad 0.86-1.04 ; \quad \mathrm{p}=0.23)$. Major cardiovascular events occurred in 1367 patients $(13.5 \%)$ in the telmisartan group and 1463 patients $(14.4 \%)$ in the placebo group (hazard ratio, 0.94; $95 \%$ CI, 0.87-1.01; $\mathrm{p}=0.11$ ). New-onset diabetes occurred in $1.7 \%$ of the telmisartan group and $2.1 \%$ of the placebo group (hazard ratio, 0.82; 95\% CI, 0.65-1.04; $\mathrm{p}=0.10)$. In this study telmisartan initiated soon after an ischemic stroke and continued for 2.5 years did not significantly lower the rate of recurrent stroke, major cardiovascular events, or diabetes. 
Am. Med.J. 1 (1): 8-22, 2010

\section{Stroke and atrial fibrillation:}

Title: Comparison of idraparinux with vitamin $\mathrm{K}$ antagonists for prevention of thromboembolism in patients with atrial fibrillation: A randomised, openlabel, non-inferiority trial.

Vitamin K antagonists such as warfarin, the current standard of treatment for prophylaxis against stroke and systemic embolism in patients with atrial fibrillation, require regular monitoring and dose adjustment. This randomized, open-label non-inferiority trial aimed to compare the efficacy and safety of idraparinux (a fixeddose, unmonitored anticoagulant regimen) with warfarin (Amadeus et al., 2008). Patients with atrial fibrillation at risk for thromboembolism were randomly assigned to receive either subcutaneous idraparinux $(2.5 \mathrm{mg}$ weekly) or adjusted-dose warfarin (target international normalised ratio of 2-3). The primary efficacy outcome was the cumulative incidence of all stroke and systemic embolism. The principal safety outcome was clinically relevant bleeding. Analyses were done by intention to treat; the non-inferiority hazard ratio was set at 1.5. The trial was stopped after randomization of 4576 patients (2283 to receive idraparinux, 2293 to receive warfarin) and a mean follow-up period of 10.7 (SD 5.4) months because of excess clinically relevant bleeding with idraparinux (346 cases Vs 226 cases; 19.7 Vs 11.3 per 100 patient-years; $\mathrm{p}<0.0001)$. There were 21 intracranial bleeds with idraparinux and 9 with vitamin $\mathrm{K}$ antagonists $(1.1 \mathrm{Vs}$ 0.4 per 100 patient-years; $p=0.014$ ); elderly patients and those with renal impairment were at greater risk of such complications. There were 18 cases of thromboembolism with idraparinux and 27 cases with vitamin $\mathrm{K}$ antagonists (0.9 Vs 1.3 per 100 patient-years; hazard ratio $0.71,95 \%$ CI $0.39-1.30 ; \mathrm{p}=0.007$ ), satisfying the non-inferiority criterion. There were 62 deaths with idraparinux and 61 with vitamin $\mathrm{K}$ antagonists (3.2 Vs 2.9 per 100 patient-years; $p=0.49$ ). The study found patients with atrial fibrillation at risk for thromboembolism, long-term treatment with idraparinux was as efficacious as warfarin, however; it caused significantly more bleeding especially intracranial bleeding.

Stroke and neuroprotectants: Unfortunately at the present time there are no readily available neuroprotective agents in post-stroke to help decrease brain tissue (penumbral) injury and improve functional recovery in the short and long-term. There were 2 trials which studied the efficacy of 2 neuroprotectants after an ischemic stroke (Amadeus et al., 2008; Weir et al., 2003).
Title: DP-b99, a membrane-activated metal ion chelator, as neuroprotective therapy in ischemic stroke. DP-b99, a chelator of zinc and calcium ions has been found to have neuroprotective properties in animal stroke models (Krakovsky et al., 2001). This multicenter, double-blind placebo-controlled randomized phase II trial assessed the safety and potential protective effects of DP-b99 in patients with acute ischemic stroke (Diener et al., 2008). Patients with signs of cortical involvement and a National Institutes of Health Stroke Scale (NIHSS) score of 7-20 received a 4 day course of intravenous $1 \mathrm{mg} \mathrm{kg}^{-1}$ day $^{-1}$ DP-b99 $(\mathrm{n}=75)$ or placebo $(\mathrm{n}=75)$ within $1-9 \mathrm{~h}$ of an ischemic stroke. Treatment with recombinant tissue plasminogen activator was not permitted. The baseline NIHSS score was 72 for DP-b99 Vs 75 for placebo-treated patients, in the intent-to-treat cohort was (mean $\pm \mathrm{SD}$ ) $12.2 \pm 4.0$ and $12.6 \pm 3.3$, the time to needle (mean $\pm \mathrm{SD}$ ) was $6: 36 \pm 1: 47$ and $6: 28 \pm 1: 33 \mathrm{~h}$ and the age was $73.3 \pm 9.9$ and $72.0 \pm 9.6$ years. The 90 -day median change from baseline (the primary end point) was -6.0 and -5.0 NIHSS points in the DP-b99 and placebo groups (nonsignificant). At 90 days, a significantly better outcome was in the DP-b99 compared with the placebo group (modified Rankin scale score of 0,1 , or same as prestroke): 30.6 and $16.0 \%$, respectively $(\mathrm{p}=0.05)$. The recovery rate was unaffected by the time to needle. Further analyses showed that the 90 day median change from baseline in patients with an entry NIHSS score was 8.0 and 5.0 points in the DP-b99 and placebo groups $(\mathrm{p}=0.03)$. No major differences in mortality rate, causes of death, adverse events, safety laboratory tests and ECG parameters were found between the 2 groups. This was a negative study as the primary end point of change in NIHSS score from baseline to 90 days was the same between the 2 groups. However, secondary end points demonstrated a significantly improved 90 day recovery rate with treatment with DPb99 compared with placebo. No major adverse events were identified.

Title: Allopurinol use yields potentially beneficial effects on inflammatory indices in those with recent ischemic stroke: A randomized, double-blind, placebocontrolled trial.

Elevated serum Uric Acid (UA) level is associated with poor outcome and increased risk of stroke recurrence (Weir et al., 2003). Allopurinol, a xanthine oxidase inhibitor lowers uric acid and also attenuates expression of inflammatory adhesion molecules in murine models, reduces oxidative stress in the vasculature and improves endothelial function (Dawson et al., 2007). This study sought to investigate 
whether allopurinol can alter expression of inflammatory markers after acute ischemic stroke. This randomized, double-blind, placebo-controlled trial investigated the safety, tolerability and effect of 6 weeks' treatment with high- (300 mg once a day) or low- (100 mg once a day) dose allopurinol on levels of UA and circulating inflammatory markers (Intercellular Adhesion Molecule-1 [ICAM-1], C-Reactive Protein (CRP) and interleukin-6 [IL-6]) after ischemic stroke (Muir et al., 2008). Fifty patients with acute ischemic stroke were enrolled (17, 17 and 16 in the high, low and placebo groups, respectively). The mean ( \pm SD) age was $70( \pm 13)$ years. Groups had similar characteristics at baseline. UA levels were significantly reduced at both 7 days and 6 weeks in the high-dose group (by $0.14 \mathrm{mmol} \mathrm{\textrm {L } ^ { - 1 }}$ at 6 weeks, $\left.\mathrm{p}=0.002\right)$. ICAM-1 concentration $\left(\mathrm{ng} \mathrm{mL}^{-1}\right.$ ) rose by 51.2 in the placebo group, by 10.6 in the low-dose allopurinol group, but fell in the high-dose group (by 2.6; difference between groups $p=0.012$, Kruskal-Wallis test). The degree of change in CRP and IL-6 levels did not reach statistical significance between the 3 groups. There were no serious adverse events. Thus Allopurinol treatment was well tolerated and high dose lowered UA and ICAM-1 levels after stroke. This study suggests the need of larger future trials to evaluate the role of allopurinol as a neuroprotectant after ischemic stroke and its effect on clinical recovery.

Antiplatelets and stroke: Recurrent stroke is a frequent, disabling event after ischemic stroke. Antiplatelet agents especially aspirin has been the mainstay of secondary prophylaxis after an ischemic stroke because it is effective and cheap. Two studies compared the efficacy and safety profile of 2 different antiplatelet agents to aspirin (Dawson et al., 2007; Muir et al., 2008).

Title: Sarpogrelate-Aspirin Comparative Clinical Study for Efficacy and Safety in Secondary Prevention of Cerebral Infarction (S-ACCESS): A randomized, double-blind, aspirin-controlled trial.

Sarpogrelate, a selective inhibitor of 5hydroxytryptamine receptors, is widely used in Japan, China and South Korea to treat patients with peripheral arterial disease due to its antiplatelet and vasodilator effect. This study compared the efficacy and safety of sarpogrelate to aspirin in Japanese ischemic stroke patients (Shinohara et al., 2008). A total of 1510 patients with recent cerebral infarction (1 week to 6 months after onset) were randomly assigned to receive either sarpogrelate $100 \mathrm{mg}$ TID $(\mathrm{n}=747)$ or aspirin $81 \mathrm{mg} \mathrm{day}^{-1}(\mathrm{n}=752)$, with a mean follow-up of
1.59 years. The primary efficacy end point was to demonstrate the noninferiority of sarpogrelate with respect to aspirin for recurrence of cerebral infarction. Cerebral infarction recurred in 72 patients $(6.09 \%$ year $\left.^{-1}\right)$ in the sarpogrelate and in $58\left(4.86 \%\right.$ year $\left.^{-1}\right)$ in the aspirin group (hazard ratio $=1.25 ; 95 \%$ CI, 0.89$1.77 ; \mathrm{p}=0.19)$. Serious vascular events occurred in 90 $\left(7.61 \%\right.$ year $\left.^{-1}\right)$ and in $85\left(7.12 \%\right.$ year $\left.^{-1}\right)$ patients, respectively (hazard ratio $=1.07 ; 95 \%$ CI, 0.80-1.44; $\mathrm{p}=0.65)$. The bleeding events were $89(11.9 \%)$ and $131(17.3 \%)$ respectively for sarpogrelate and aspirin $(\mathrm{p}<0.01)$. In this study sarpogrelate was noninferior to aspirin for prevention of recurrence of cerebral infarction and had significantly fewer bleeding events than aspirin.

Title: Aspirin and Extended-Release Dipyridamole versus Clopidogrel for Recurrent Stroke. (Prevention Regimen for Effectively Avoiding Second Strokes (PRoFESS) Study Group).

This study compared the efficacy and safety of two antiplatelet regimens-aspirin plus extended-release dipyridamole (ASA-ERDP) versus clopidogrel, in a double-blind, 2-by-2 factorial trial (Sacco et al., 2008). Patients were randomly assigned to receive $25 \mathrm{mg}$ of aspirin plus $200 \mathrm{mg}$ of extended-release dipyridamole twice daily or $75 \mathrm{mg}$ of clopidogrel daily. The primary outcome was first recurrence of stroke. The secondary outcome was a composite of stroke, myocardial infarction, or death from vascular causes. A total of 20,332 patients were followed for a mean of 2.5 years. Recurrent stroke occurred in 916 patients $(9.0 \%)$ receiving ASA-ERDP and in 898 patients (8.8\%) receiving clopidogrel (hazard ratio, 1.01 ; $95 \%$ Confidence Interval (CI), 0.92-1.11). The secondary outcome occurred in 1333 patients (13.1\%) in each group (hazard ratio for ASA-ERDP, 0.99; 95\% CI, 0.92-1.07). There were more major hemorrhagic events among ASA-ERDP (419 [4.1\%]) than among clopidogrel recipients (365 [3.6\%]) (hazard ratio, 1.15; $95 \% \mathrm{CI}, 1.00-1.32)$, including intracranial hemorrhage (hazard ratio, 1.42; 95\% CI, 1.11-1.83). The net risk of recurrent stroke or major hemorrhagic event was similar in the two groups (1194 ASA-ERDP [11.7\%], Vs 1156 clopidogrel recipients [11.4\%]; hazard ratio, 1.03; 95\% CI, 0.95-1.11). This trial did not meet the predefined statistical criteria for noninferiority (margin of 1.075) and showed similar rates of recurrent stroke for the two antiplatelet agents.

\section{Stroke and hyperglycaemia:}

Title: Treatment of Hyperglycemia in Ischemic Stroke (THIS): A randomized pilot trial. Hyperglycemia 
during acute cerebral infarction has been shown to worsen brain injury (Baird et al., 2003). This study tested the feasibility and tolerability of aggressive hyperglycemia correction with intravenous insulin compared with usual care during acute cerebral infarction (Bruno et al., 2008). This randomized, multicenter, blinded pilot trial was conducted in patients with cerebral infarction within $12 \mathrm{~h}$ after onset, with a baseline glucose value $\geq 8.3 \mathrm{mmol} \mathrm{L}^{-1}$ $\left(\geq 150 \mathrm{mg} \mathrm{dL}^{-1}\right)$ and a National Institutes of Health Stroke Scale (NIHSS) score of 3-22. Patients were randomized 2:1 to aggressive treatment with continuous intravenous insulin or subcutaneous insulin QID as needed (usual care). The target glucose levels were $<7.2 \mathrm{mmol} \mathrm{L}^{-1}\left(<130 \mathrm{mg} \mathrm{dL}^{-1}\right)$ in the aggressivetreatment group and $<11.1 \mathrm{mmol} \mathrm{L}^{-1}\left(<200 \mathrm{mg} \mathrm{dL}^{-1}\right)$ in the usual-care group. Glucose was monitored every 1$2 \mathrm{~h}$ and the protocol treatments continued for up to 72 h. Final clinical outcomes were assessed at 3 months. Thirty one patients were randomized to aggressive treatment and 15 to usual care. All of the patients in the aggressive-treatment group and $11(73 \%)$ in the usualcare group had diabetes $(\mathrm{p}=0.008)$. Glucose levels were significantly lower in the aggressive-treatment group throughout protocol treatment $\left(7.4 \mathrm{Vs} 10.5 \mathrm{mmol} \mathrm{L}^{-1}\right.$ (133 Vs $190 \mathrm{mg} \mathrm{dL} \mathrm{dL}^{-1}$, $\left.\mathrm{p}<0.001\right)$. Hypoglycemia $<3.3 \mathrm{mmol} \mathrm{L}^{-1}\left(<60 \mathrm{mg} \mathrm{dL}^{-1}\right)$ occurred only in the aggressive-treatment group (11 patients, (35\%), 4 (13\%) of whom had brief autonomic symptoms and 1 patient had cognitive-slowing which resolved with $25 \mathrm{~mL}$ of $50 \%$ dextrose administration. The clinical outcomes (modified Rankin scale, Barthel Index, NIHSS and Stroke Specific Quality of life Scale) were similar between the treatment groups. The authors of the study concluded that aggressive intravenous insulin corrected hyperglycemia during acute cerebral infarction was feasible without major adverse events, however; it is of questionable clinical efficacy. This trial like the recent GIST-UK study showed no significant clinical benefit is achieved in aggressively managing hyperglycaemia (Gray et al., 2007).

Antibiotic prophylaxis in acute stroke: Fever after stroke is a strong predictor for a poor outcome with infections as the most common cause. Infection is a leading cause of death acutely post-stroke.

Title: The Mannheim Infection in Stroke Study (MISS).

This pilot study evaluated the effects of prophylactic antibiotic therapy on the incidence and degree of fever after acute ischemic stroke. In this randomized study patients with ischemic stroke were enrolled within $24 \mathrm{~h}$ from clinical onset who were severely disabled (modified Rankin Scale (mRS) score >3) with no infection (Schwarz et al., 2008). Interventions included prophylactic mezlocillin plus sulbactam ( 2 g plus $1 \mathrm{~g}$ IV over 20 min every $8 \mathrm{~h}$ for 4 days) or conventional management. Over 10 days, body temperature was continuously monitored and the presence of infection was daily assessed. Primary end points were incidence and degree of fever; secondary end points included rate of infection and clinical outcome. There were 60 patients with a mean age of 75 years and median National Institutes of Health Stroke Scale score of 16. Over the first 3 days, patients in the intervention group had lower mean body temperatures and lower daily peak temperatures $(\mathrm{p}<0.05)$. Throughout the 10 days observation period, 15 of 30 patients in the intervention group Vs 27 of 30 patients in the conventionally treated group developed an infection $(p<0.05)$. Mean interval until the diagnosis of infection was 5.1 days in the intervention group and 3.3 days in the control group $(p<0.05)$. Clinical outcome (defined by the mRS) favored patients with prophylactic antibiotic therapy $(\mathrm{p}=0.01)$. This study concluded that in patients with acute severe stroke, prophylactic administration of mezlocillin plus sulbactam over 4 days decreased body temperature, lowered the rate of infection and was associated with a better clinical outcome.

Title: Preventive ANtibacterial THERapy in acute Ischemic Stroke (PANTHERIS): A randomized controlled trial.

In a mouse model, preventive antibacterial therapy with moxifloxacin prevented the development of poststroke infections, reduced mortality and improved neurological outcome significantly. This study investigated whether this approach was effective in stroke patients. In this randomized, double-blind, placebo-controlled trial in 80 patients with severe, NonLacunar, Ischemic Stroke (NIHSS>11) in the Middle Cerebral Artery (MCA) territory, patients received either intravenous moxifloxacin (400 mg daily) or placebo for 5 days starting within $36 \mathrm{~h}$ after stroke onset. Primary endpoint was infection within 11 days. Secondary endpoints included neurological outcome, survival, development of stroke-induced immunodepression and induction of bacterial resistance. On intention-to treat analysis (79 patients), the infection rate at day 11 in the moxifloxacin treated group was $15.4 \%$ compared to $32.5 \%$ in the placebo treated group $(\mathrm{p}=0.114)$. On per protocol analysis $(n=66)$, moxifloxacin significantly reduced infection rate from $41.9-17.1 \%(\mathrm{p}=0.032)$. Stroke associated infections were associated with a lower survival rate. In 
this study, neurological outcome and survival were not influenced by treatment with moxifloxacin. On logistic regression analysis, treatment arm as well as the interaction between treatment arm and monocytic HLADR expression (a marker for immunodepression) at day 1 after stroke onset was independently and highly predictive for post-stroke infections. This study suggests that preventive administration of moxifloxacin was superior in reducing infections after severe nonlacunar ischemic stroke compared to placebo. In addition, the results emphasize the pivotal role of immunodepression in developing post-stroke infections.

\section{Post-stroke depression:}

Title: Escitalopram and problem-solving therapy for prevention of poststroke depression: a randomized controlled trial.

Depression occurs in a third of patients post stroke (Goodwin and Devanand, 2008; Rabadi et al., 2008). Since poststroke depression has been associated with both impaired recovery in activities of daily living and increased mortality, prevention of depression represents an important goal. This study tried to determine whether treatment with escitalopram or problemsolving therapy in non-depressed stroke patients during their first year following acute stroke will decrease the number of depression cases compared to placebo (Robinson et al., 2008). In this multi-center randomized, double-blind, placebo-controlled trial of 176 non-depressed patients conducted within 3 months following acute stroke there were 3 groups: Escitalopram $(\mathrm{n}=59)$, placebo $(\mathrm{n}=58)$ and a nonblinded problem-solving therapy group $(n=59)$. The main outcome measure was the development of major or minor poststroke depression based on symptoms elicited by the Structured Clinical Interview for the Diagnostic and Statistical Manual of Mental Disorders (Fourth Edition) (DSM-IV) and the diagnostic criteria from DSM-IV for depression due to stroke with major depressive-like episode or minor depression (i.e., research criteria). Patients in the placebo group developed more depression than individuals who received escitalopram (11 major and 2 minor cases of depression $(22.4 \%)$ Vs 3 major and 2 minor cases of depression [8.5\%], adjusted Hazard Ratio (HR), 4.5; 95\% Confidence Interval (CI), 2.4-8.2; $\mathrm{p}<0.001)$ and individuals who received problemsolving therapy (5 major and 2 minor cases of depression [11.9\%], adjusted HR, 2.2; 95\% CI, 1.4-3.5; $\mathrm{p}<0.001)$. These results were unchanged after accounting for confounders such as age, sex, treatment site, prior history of mood disorders and severity of stroke impairment. On an intention-to-treat basis, which assumed that all 27 patients who did not start randomized treatment would develop depression and controlling for prior history of mood disorders, escitalopram was superior to placebo $(23.1 \%$ Vs $34.5 \%$; adjusted HR, 2.2; 95\% CI, 1.2-3.9; p = 0.007), while problem-solving therapy was no different than placebo (30.5 Vs 34.5\%; adjusted HR, 1.1; 95\% CI, 0.8-1.5; $\mathrm{p}=0.051)$. Adverse events, including all-cause hospitalizations, nausea and adverse effects associated with escitalopram were not different between the 3 groups. In this study of non-depressed patients with recent stroke, the use of escitalopram or problemsolving therapy significantly lowered the incidence of depression over 12 months of treatment compared with placebo, but problem-solving therapy did not achieve significant results over placebo on the intention-to-treat method of analysis.

\section{Vascular dementia:}

Title: Donepezil in patients with subcortical vascular cognitive impairment: a randomized double-blind trial in CADASIL.

Vascular cognitive impairment may be due to cholinergic deficits. Trials of cholinesterase inhibitors in patients with vascular dementia have been difficult because of the heterogeneous disease mechanisms and overlap between vascular and Alzheimer's Disease (AD) pathology in the age-group recruited. Cerebral Autosomal Dominant Arteriopathy with Subcortical Infarcts and Leucoencephalopathy (CADASIL), a genetic form of subcortical ischemic vascular dementia represents a homogeneous disease process and because of CADASIL's early onset co-morbid AD pathology is rare. In this multicentre, 18 week, placebo-controlled, double-blind, randomized parallel-group trial determined whether the cholinesterase inhibitor donepezil improved cognition in patients with CADASIL (Dichgans et al., 2008). One hundred and sixty eight patients with CADASIL (mean age 54.8 years) were randomly assigned to either $10 \mathrm{mg}$ donepezil $\operatorname{day}^{-1}(\mathrm{n}=86)$ or placebo $(\mathrm{n}=82)$ by a computer-generated protocol. Inclusion criteria included a Mini-Mental State Examination (MMSE) score of 10-27 or a Trail Making Test (TMT) B time score at least 1.5 SD below the mean, after adjustment for age and education. The primary endpoint was change from baseline in the score on the vascular AD assessment scale cognitive subscale (V-ADAS-cog) at 18 weeks. Secondary endpoints included scores on the ADAS-cog, MMSE, TMT A time and B time, Stroop, executive interview-25 (EXIT-25), CLOX, disability assessment for dementia and sum of boxes of the clinical dementia rating scale. Analysis was by 
intention to treat. There was no significant difference between donepezil $(n=84)$ and placebo $(n=77)$ in the primary endpoint (V-ADAS-cog score). The leastsquares mean change from baseline score was -0.81 (SE 0.59 ) in the placebo and -0.85 (SE 0.57) in the donepezil group $(\mathrm{p}=0.96)$. There was a significant treatment effect favoring donepezil on the following secondary outcomes: TMT B time $(\mathrm{p}=0.02)$, TMT A time $(\mathrm{p}=0.015)$ and EXIT-25 $(\mathrm{p}=0.02)$. Ten donepezil-treated patients discontinued treatment due to adverse events compared to seven placebo-treated patients. Thus donepezil had no effect on the primary endpoint (the V-ADAS-cog score) in CADASIL patients with cognitive impairment. Improvements were noted on several measures of executive function but the clinical relevance of these findings is unclear.

Stroke and subarachnoid hemorrhage: Cerebral infarction secondary to vasospasm after an aneurysmal rupture is a dreaded complication. It is responsible for poor functional outcome in these patients. Three studies tried to address how best to prevent this delayed cerebral artery vasospasm (Chou et al., 2008; Macdonald et al., 2008; Ryttlefors et al., 2008).

Title: A randomized, double-blind, placebo-controlled pilot study of simvastatin in aneurysmal subarachnoid hemorrhage.

Studies suggest statins ameliorate aneurysmal Subarachnoid Hemorrhage (SAH)-induced cerebral vasospasm and ischemic complications. This study tested the safety and feasibility of simvastatin $80 \mathrm{mg} \mathrm{day}^{-1}$ for vasospasm prevention in SAH patients (Chou et al., 2008). Thirty-nine statin-naïve Fisher grade 3 SAH subjects were double-blind randomized to receive simvastatin $80 \mathrm{mg} \mathrm{day}^{-1}(\mathrm{n}=19)$ or placebo $(\mathrm{n}=20)$, stratified by Hunt and Hess grade. Primary end points were death and drug morbidity. Angiographicallyconfirmed vasospasm occurred in 8/20 placebo and $5 / 19$ simvastatin-treated subjects. Vasospasm-related ischemic infarcts developed in 5/20 placebo and 2/19 simvastatin-treated subjects. Death was $3 / 20$ in the placebo and 0/19 in the simvastatin group. Study drug was withdrawn in 1 subject in each treatment group for reversible liver enzyme or creatine phosphokinase elevation. Simvastatin was found to be safe and feasible after $\mathrm{SAH}$ in preventing vasospasm-related delayed cerebral ischemia. However, a larger study is needed to test its efficacy in preventing SAH-induced vasospasm.

Title: Clazosentan to Overcome Neurological Ischemia and Infarction Occurring after Subarachnoid
Hemorrhage (CONSCIOUS-1): Randomized, doubleblind, placebo-controlled phase 2 dose-finding trial.

This randomized, double-blind, placebo-controlled, dose-finding study assessed efficacy and safety of 1, 5 and $15 \mathrm{mg} \mathrm{h}^{-1}$ intravenous clazosentan, an endothelin receptor antagonist, in preventing vasospasm after aneurysmal subarachnoid hemorrhage (Macdonald et al., 2008). Four hundred and thirteen patients were randomized to placebo or clazosentan within $56 \mathrm{~h}$ and continued up to 14 days after initiation of treatment. The primary end point was moderate or severe angiographic vasospasm based on centrally read, blinded evaluation of digital subtraction angiography at baseline and 7-11 days post-subarachnoid hemorrhage. The secondary end point, included all-cause mortality, new cerebral infarct from any cause, delayed ischemic neurological deficit due to vasospasm, or use of rescue therapy. Clinical outcome was assessed by the extended Glasgow Outcome Scale at 12 weeks. Moderate or severe vasospasm was reduced in a dose-dependent fashion from $66 \%$ in the placebo group to $23 \%$ in the $15 \mathrm{mg} \mathrm{h}^{-1}$ clazosentan group (risk reduction, $65 ; 95 \%$ CI, 47-78\%; p $<0.0001$ ). No significant effects were seen on secondary end points. On post hoc analysis for cerebral infarcts and delayed ischemic neurological deficit due to vasospasm on central review a trend favoring clazosentan (37, 28 and $29 \%$ in the 1, 5 and $15 \mathrm{mg} \mathrm{h}^{-1}$ groups versus $39 \%$ in the placebo group, nonsignificant) was seen. Clazosentan had increased rates of pulmonary complications, hypotension and anemia. The study concluded that clazosentan significantly decreased moderate and severe vasospasm in a dose-dependent manner and there was a trend for reduction in vasospasm-related morbidity/mortality in patients with aneurysmal subarachnoid hemorrhage when centrally assessed. Overall, the adverse effects were not serious.

Title: Effect of prophylactic transluminal balloon angioplasty on cerebral vasospasm and outcome in patients with Fisher grade III Subarachnoid Hemorrhage (SAH): Results of a phase II multicenter, randomized, clinical trial.

Prophylactic Transluminal Balloon Angioplasty (pTBA) has been shown to prevent delayed ischemic neurological deficit in a pilot study (Muizelaar et al., 1999). In this phase II multicenter randomized clinical trial of 170 patients with Fisher Grade III Subarachnoid Hemorrhage (SAH), 85 patients were randomized to the treatment group and underwent pTBA within $96 \mathrm{~h}$ after SAH (Zwienenberg-Lee et al., 2008). The primary outcome measures were: Glasgow Outcome Score (GOS) at 3 months, development of Delayed Ischemic Neurological Deficit (DIND), occurrence of 
Transcranial Doppler (TCD) vasospasm and length of stay in the ICU and hospital. Overall pTBA resulted in an absolute risk reduction of $5.9 \%$ and a relative risk reduction of $10.4 \%$ unfavorable outcome $(\mathrm{p}=0.54)$. Good grade patients had absolute and relative risk reductions of respectively 9.5 and $29.4 \%(p=0.73)$. The incidence of DIND was lower in the pTBA group $(\mathrm{p}=0.30)$ and fewer patients required therapeutic angioplasty to treat DIND $(\mathrm{p}=0.03)$. Length of stay in ICU and hospital was similar in both treated and the control groups. 4 patients had a procedure-related vessel perforation, of which 3 patients died. This trial was unsuccessful as defined by the primary end point (GOS). Fewer patients developed vasospasm after treatment with pTBA and significantly decreased the need for therapeutic angioplasty. Thus pTBA was unable to improve the poor outcome of patients with Fisher grade III SAH.

\section{Stroke and surgery:}

Title: International subarachnoid aneurysm trial of neurosurgical clipping versus endovascular coiling: Subgroup analysis of 278 elderly patients.

It is often thought that elderly patients in particular would benefit from endovascular aneurysm treatment. This study compared the efficacy and safety of endovascular coiling (EVT) with neurosurgical clipping (NST) in the subgroup of elderly SAH patients in the
International Subarachnoid Aneurysm Trial (ISAT) ${ }^{[36]}$. A cohort 278 SAH patients, 65 years or older, were enrolled in the ISAT. The patients were randomly allocated to EVT $(n=138)$ or NST $(n=140)$. The primary outcome was the proportion of patients with a modified Rankin scale score of 0-2 (independent survival) at 1 year after the SAH. The rates of procedural complications and adverse events were also recorded. Of the patients allocated to EVT 83 of 138 $(60.1 \%)$ were independent compared to 78 of 140 $(56.1 \%)$ allocated NST (NS). Of the patients with internal carotid and posterior communicating artery aneurysms allocated to EVT 36 of 50 (72.0\%) were independent compared to 26 of $50(52.0 \%)$ allocated NST $(p<0.05)$. Of the patients with middle cerebral artery aneurysms allocated to EVT 10 of 22 (45.5\%) were independent compared to 13 of 15 (86.7\%) allocated NST $(\mathrm{p}<0.05)$. The epilepsy frequency was $0.7 \%$ in the EVT compared to $12.9 \%$ in the NST group $(\mathrm{p}<0.001)$. The study concluded that in good grade elderly SAH patients with small anterior circulation aneurysms, EVT is probably the favored treatment for ruptured internal carotid and posterior communicating artery aneurysms, while elderly patients with ruptured middle cerebral artery aneurysms benefit from NST. EVT results in a lower epilepsy frequency than NST.

A summary of these RCTs in acute Stroke in 2008 is presented in Table 1.

Table 1: Summary of the randomized control trials undertaken in stroke in 2008

\begin{tabular}{|c|c|c|c|c|c|}
\hline References & $\begin{array}{l}\text { Time to randomization } \\
\text { post-stroke }\end{array}$ & Set-up & Sample size & Invention & Main findings \\
\hline \multicolumn{6}{|c|}{ Thrombolytic and stroke } \\
\hline $\begin{array}{l}\text { Adams et al. } \\
\text { (2008) }\end{array}$ & $\begin{array}{l}\text { On awakening } \\
(<3 \mathrm{~h}) \text { Vs mainly } \\
\text { within } 5 \text { h of acute } \\
\text { is chemic stroke VS } \\
\text { between } 5-6 \mathrm{~h} \\
\text { of an acute ischemic } \\
\text { stroke }\end{array}$ & $\begin{array}{l}\text { Acute } \\
\text { hospitalization }\end{array}$ & $\begin{array}{l}\text { Planned enrollment } \\
1800 \text { patients; Enrolled } 801, \\
\text { Abciximab }=403 \\
\text { Placebo }=398 \\
\text { On awakening: } \mathrm{A}=22, \\
\mathrm{p}=21 \text { within } 5 \mathrm{~h}: \\
\mathrm{A}=221, \mathrm{p}=218 \\
\text { between } 5-6: \\
\mathrm{A}=160, \mathrm{p}=159\end{array}$ & $\begin{array}{l}\text { Intravenous abciximab: } \\
\text { Bolus } 0.25 \mathrm{mg} \mathrm{kg}^{-1} \\
\text { followed by } 12 \mathrm{~h} \\
\text { infusion }\left(0.125 \mu \mathrm{gm} \mathrm{kg}^{-1} \mathrm{~min}^{-1}\right. \\
\text { to max } 10 \mu \mathrm{gm} \mathrm{min} \\
\text { VS placebo }\end{array}$ & $\begin{array}{l}\text { The trial was halted after having enrolled } \\
808 \text { patients in all cohorts by the independent } \\
\text { safety and efficacy monitoring board as risk } \\
\text { outweighed the benefit for abciximab. Within } \\
5 \text { days of enrollment, } 5.5 \% \text { of abciximab- } \\
\text { treated and } 0.5 \% \text { of placebo-treated patients } \\
\text { had symptomatic or fatal intracranial } \\
\text { hemorrhage }(\mathrm{p}=0.002) \text {. The trial did not } \\
\text { show improvement in the primary outcome } \\
\text { measure with abciximab. }\end{array}$ \\
\hline $\begin{array}{l}\text { Davis et al. } \\
(2008)\end{array}$ & $\begin{array}{l}3-6 \mathrm{~h} \text { of an acute } \\
\text { ischemic stroke }\end{array}$ & $\begin{array}{l}\text { Acute } \\
\text { hospitalization }\end{array}$ & $\begin{array}{l}101 \\
\text { Alteplase }=52 \\
\text { Placebo }=49\end{array}$ & $\begin{array}{l}\text { IV Alteplase } 0.9 \mathrm{mg} \mathrm{kg}^{-1} \\
\text { to max } 90 \mathrm{mg} ; 10 \% \text { as } \\
\text { bolus and reminder } \\
\text { over } 1 \mathrm{~h} \mathrm{Vs} \mathrm{placebo}\end{array}$ & $\begin{array}{l}\text { The mean infarct growth was } 1.24 \text { with } \\
\text { alteplase and } 1.78 \text { with placebo (ratio } 0.69 \text {, } \\
p=0.239) \text {; the median relative infarct growth } \\
\text { was } 1.18 \text { with alteplase and } 1.79 \text { with placebo } \\
\text { (ratio } 0.66, p=0.054) \text {. With alteplase } \\
\text { reperfusion was commonly seen with less } \\
\text { infarct growth }(p=0.001) \text {, better neurological } \\
\text { outcome }(p<0.0001) \text { and better functional } \\
\text { outcome }(p=0.010) \text {. }\end{array}$ \\
\hline $\begin{array}{l}\text { Hacke et al. } \\
(2008)\end{array}$ & $\begin{array}{l}\text { Between } 3 \text { and } \\
4.5 \mathrm{~h} \text { after the } \\
\text { onset of a stroke }\end{array}$ & $\begin{array}{l}\text { Acute } \\
\text { hospitalization }\end{array}$ & $\begin{array}{l}821 ; \\
\text { Alteplase }=418 \\
\text { Placebo }=403\end{array}$ & $\begin{array}{l}\text { IV Alteplase } \\
0.9 \mathrm{mg} \mathrm{kg}^{-1} \text { to } \max \\
90 \mathrm{mg} ; 10 \% \text { as } \\
\text { bolus and reminder } \\
\text { over } 1 \mathrm{~h} \mathrm{Vs} \text { placebo }\end{array}$ & $\begin{array}{l}\text { Patients on alteplase had a favorable outcome } \\
\text { than with placebo }(52.4 \% \text { Vs } 45.2 \% ; p=0.04) \\
\text { on the mRS score of } 0 \text { to } 1 . \text { The incidence of } \\
\text { intracranial hemorrhage was higher with } \\
\text { alteplase than with placebo }(27.0 \% \text { VS } \\
17.6 \% ; p=0.001 \text {; for symptomatic } \\
\text { intracranial hemorrhage, } 2.4 \% \text { Vs } 0.2 \% \text {; } \\
p=0.008) \text {. Mortality did not differ between } \\
\text { the two groups ( } 7.7 \text { and } 8.4 \% \text {, respectively; } \\
p=0.68)\end{array}$ \\
\hline
\end{tabular}


Am. Med. J. 1 (1): 8-22, 2010

Table 1: Continued

\begin{tabular}{|c|c|c|c|c|}
\hline $\begin{array}{l}\text { Christou et al. } \\
\text { (2002) }\end{array}$ & $\begin{array}{l}\text { Within } 3 \mathrm{~h} \text { of an } \\
\text { acute ischemic stroke }\end{array}$ & $\begin{array}{l}\text { Acute } \\
\text { hospitalization }\end{array}$ & $\begin{array}{l}94 ; \\
\text { Tier } 1=40 \\
\text { Tier } 2=54 \text { the } \\
\text { combine group of the } \\
2 \text { dose tiers }(n=69) \\
\text { t-PA group }=25\end{array}$ & $\begin{array}{l}\text { Low-dose t-PA } \\
\text { (tier } 1=0.3 \mathrm{mg} \mathrm{kg}^{-1}, \\
\left.\text { tier } 2=0.45 \mathrm{mg} \mathrm{kg}^{-1}\right) \\
\text { plus eptifibatide } \\
(75 \text { mug kg-1 bolus } \\
\text { followed by } 0.75 \text { mug kg} \\
\text { per min infusion for } \\
2 \mathrm{~h} \text { ) Vs standard-dose } \\
\text { rt-PA }\left(0.9 \mathrm{mg} \mathrm{kg}^{-1}\right) \text {. }\end{array}$ \\
\hline $\begin{array}{l}\text { Pancioli et al. } \\
(2008)\end{array}$ & $\begin{array}{l}\text { Within } 3 \mathrm{~h} \text { of an } \\
\text { acute stroke }\end{array}$ & $\begin{array}{l}\text { Acute } \\
\text { hospitalization }\end{array}$ & $\begin{array}{l}37 ; \\
\text { Doppler U. Sound }=19 \\
\text { Control }=18\end{array}$ & $\begin{array}{l}\text { Effectiveness of } \\
\text { sonothrombolysis with } \\
1.8 \mathrm{~Hz} \text { doppler } \\
\text { ultrasound for } \\
1 \mathrm{~h} \text { transcranially }\end{array}$ \\
\hline
\end{tabular}

\begin{tabular}{|c|c|c|c|}
\hline $\begin{array}{l}\text { Alexandrov } \\
\text { et al. (2004) }\end{array}$ & $\begin{array}{l}\text { Within } 3 \mathrm{~h} \text { of } \\
\text { their acute stroke }\end{array}$ & $\begin{array}{l}\text { Acute } \\
\text { hospitalization }\end{array}$ & $\begin{array}{l}15 ; \\
\text { Experimental group tPA + } \\
\text { TCD }+2.8 \mathrm{~mL} \mu \mathrm{S})=12 \\
\text { Control group } \\
(\mathrm{tPA}+\mathrm{TCD})=3\end{array}$ \\
\hline \multicolumn{4}{|c|}{ Hypertension and stroke } \\
\hline $\begin{array}{l}\text { Alexandrov } \\
\text { et al. }(2008)\end{array}$ & $\begin{array}{l}\text { Patients } \geq 80 \text { years } \\
\text { with sustained } \\
\mathrm{SBP}>160 \mathrm{mmHg}\end{array}$ & $\begin{array}{l}\text { Outpatient } \\
\text { setting }\end{array}$ & $\begin{array}{l}3845 ; \\
\text { Treatment }=1933 \\
\text { Placebo }=1912\end{array}$ \\
\hline
\end{tabular}

Ultrasound activated perflutren-lipid microspheres $(\mu \mathrm{S})$ induced recanalization with IV tissue plasminogen activator (t-PA) Vs t-PA only

The study was halted by the independent data safety monitoring board because on their review the safety profile of combination therapy (reduced-dose t-PA plus eptifibatide) to be safe in acute ischemic stroke trials. However, there was a trend toward increased clinical efficacy in the standard-dose t-PA compared to the combination treatment group.

Recanalization (complete or partial) after $1 \mathrm{~h}$ occurred in $57.9 \%$ of the US and $22.2 \%$ of the control group $(p=0.04)$. After 90 days, 4 subjects from the US had a modified rankin score $\leq 1$ (none from the control group; $\mathrm{p}=0.106$ ) and 8 had a Barthel Index $\geq 95$ (none from the control group; $\mathrm{p}=0.003$ ). Three subjects from the US (15.8\%) and one $(5.6 \%)$ in the control group $(\mathrm{p}=0.60)$ developed symptomatic intracranial bleed. Perflutren $\mu \mathrm{S}$ was able to reach beyond intracranial occlusions, achieve a higher recanalization rate $(42 \%)$ with no increase in symptomatic intrcraia hemorrhage after systemic thrombolysis.

Indapamide SR $1.5 \mathrm{mg}$

At 2 years, the mean BP sitting was with or without perindopril $\quad 15.0 / 6.1 \mathrm{~mm} \mathrm{Hg}$ lower in the active than in ( $2 \mathrm{mg}$ or $4 \mathrm{mg}$ ) daily or placebo the placebo group. In an intention-to-treat analysis, active treatment was associated with a $30 \%$ reduction in the rate of fatal or nonfatal stroke $(\mathrm{p}=0.06)$. Reduction in the rate of death was: $39 \%$ from stroke $(\mathrm{p}=0.05), 21 \%$ from any cause $(p=0.02), 23 \%$ from cardiovascular causes $(\mathrm{p}=0.06)$. A $64 \%$ reduction in the rate of heart failure $(p<0.001)$. Fewer adverse events were reported in the active-treatment $(358, \mathrm{Vs} 448$ in the placebo group; $\mathrm{p}=0.001$ )

$\begin{array}{llll}\text { Chitravas et al. } & \leq 15 \text { days of an acute } & \text { Acute hospital } & 20,332 ; \\ (2007) & \text { ischemic stroke } & \begin{array}{l}\text { followed by } \\ \text { out-patient }\end{array} & \text { Telmisartan }=10,146) \\ & & \text { Placebo }=10,186\end{array}$

Telmisartan $80 \mathrm{mg}$ daily Vs placebo

During a mean follow-up of 2.5 years, the mean $\mathrm{BP}$ was 3.8/2.0 $\mathrm{mm} \mathrm{Hg}$ lower in the telmisartan than in the placebo group. A total of 880 patients $(8.7 \%)$ in the telmisartan and 934 patients $(9.2 \%)$ in the placebo group had a subsequent stroke $(\mathrm{p}=0.23)$. Major cardiovascular events occurred in 1367 patients $(13.5 \%)$ in the telmisartan and 1463 patients $(14.4 \%)$ in the placebo group $(\mathrm{p}=0.11)$. New-onset diabetes occurred in $1.7 \%$ of the telmisartan and $2.1 \%$ of the placebo group $(\mathrm{p}=0.10)$.

Atrial fibrillation and stroke Beckett et al. Patients with atria (2008) $\quad$ fibrillation

Out-patient 4576; Idraparinux $=2283$ setting Warfarin $=2293$

Idraparinux S/c $2.5 \mathrm{mg}$ weekly Vs warfarin) (INR 2-3

The trial was stopped after a mean follow-up period of 10.7 (SD 5.4) months because of excess clinically relevant bleeding with idraparinux (346 Vs 226 cases; $\mathrm{p}<0.0001$ ). There were 21 intracranial bleeding with idraparinux and 9 with vitamin $\mathrm{K}$ antagonists $(\mathrm{p}=0.014) \mathrm{sp}$. in elderly patients and those with renal impairment were at greatest risk. There were 18 cases of thromboembolism with idraparinux and 27 cases with vitamin $\mathrm{K}$ antagonists $(\mathrm{p}=0.007)$ and 62 deaths with idraparinux and 61 with vitamin $\mathrm{K}$ antagonists $(\mathrm{p}=0.49)$.

Neuroprotection and stroke Amadeus et al. $\leq 9 \mathrm{~h}$ of ischemic (2008) stroke

$\begin{array}{ll}\text { Acute } & 150 \\ \text { hospitalization } & \text { DP-b99 }=75 \\ & \text { Placebo }=75\end{array}$

DP-b99 intravenous

$1 \mathrm{mg} \mathrm{kg}^{-1}$ per day as a $2 \mathrm{~h}$ infusion for 4 days VS placebo
The 90-day median change from baseline was similar for NIHSS score for the 2 groups. At 90 days, a significantly better outcome was in the DP-b99 on the modified Rankin scale score of 0,1 , or same as prestroke) $(\mathrm{p}=0.05)$. The recovery rate was unaffected by the time to needle. 
Am. Med.J. 1 (1): 8-22, 2010

Table 1: Continued

$\begin{array}{lllll}\text { Weir } \text { et al. } & \text { Within } 3 \text { days of an } & \text { Acute } & 50 ; & \text { Treatment with high } \\ \text { (2003) } & \text { acute ischemic stroke } & \text { hospitalization } & \text { Allopurinol high dose }=17 & -300 \text { mg once a day or low } \\ & & & \text { Allopurinol low dose }=17 & -100 \text { mg once a day dose } \\ & & \text { Placebo }=16 & \text { of Allopurinol Vs placebo }\end{array}$

Uric acid levels were significantly reduced at

7 days and 6 weeks in the high-dose group (by

$0.14 \mathrm{mmol} \mathrm{L}^{-1}$ at 6 weeks, $\mathrm{p}=0.002$ ). ICAM-1

concentration $\left(\mathrm{ng} \mathrm{mL}^{-1}\right)$ rose by 51.2 in the

placebo, by 10.6 in the low-dose Allopurinol, but fell in the high-dose group (by 2.6; $p=0.012$ ). The degree of change in CRP and did not reach statistical significance between IL-6 levels the 3 groups. There were no serious adverse events.

Antiplatelets and stroke

$\begin{array}{lllll}\text { Dawson } \text { et al. } & \leq 24 \text { weeks after an } & \text { Out-patient } & 1510 ; & \text { Sarpogrelate } 100 \mathrm{mg} \\ (2007) & \text { acute ischemic stroke } & \text { setting } & \text { Sarpogrelate }=752 & \text { TID Vs aspirin } \\ & & & \text { Aspirin }=758 & 81 \text { mg day }^{-1}\end{array}$

Cerebral infarction recurred in 72 patients in the sarpogrelate and in 58 in the aspirin group $(\mathrm{p}=0.19)$. Serious vascular events occurred in 90 and in 85 patients respectively $(p=0.65)$. The incidence of bleeding events were 89 and 131 respectively $(\mathrm{p}<0.01)$.

Recurrent stroke occurred in 916 patients $(9.0 \%)$ receiving ASA-ERDP and in 898 patients $(8.8 \%)$ receiving clopidogrel. The secondary outcome occurred in 1333 patients $(13.1 \%)$ in each group. There were more major hemorrhagic events in ASA-ERDP $(419[4.1 \%])$ than in the clopidogrel recipients (365 [3.6\%]), including intracranial emorrhage.

Hyperglycaemia and stroke

Sacco et al. Within $12 \mathrm{~h}$ of an Acute 46;

(2008) acute ischemic stroke hospitalization Aggressive $=31$

with continuous IV

insulin Vs

Usual care

with subcutaneous

insulin QID as needed

Antibiotic prophylaxis in acute stroke

$\begin{array}{llll}\begin{array}{l}\text { Bruno et al. } \\ (2008)\end{array} & \text { Within } 24 \mathrm{~h} \text { of } & \text { Acute } & 60 ; \\ \text { ischemic stroke } & \text { hospitalization } & \text { Intervention }=30 \\ & & & \text { Conventional = 30 }\end{array}$

Mezlocillin + sulbactam $(2 \mathrm{~g}+1 \mathrm{~g}$ IV infusion over 20 min every $8 \mathrm{~h}$ for 4 days) VS conventional management.

$\begin{array}{lllll}\text { Schwarz } \text { et al. } & \text { Within } 36 \mathrm{~h} \text { of } & \text { Acute } & 80 ; & \text { Moxifloxacin } \\ (2008) & \text { ischemic stroke } & \text { hospitalization } & \text { Moxifloxacin }=40 & 400 \mathrm{mg} \text { daily or } \\ & & \text { Placebo }=40 & \text { placebo for 5 days }\end{array}$

Post-stroke depression

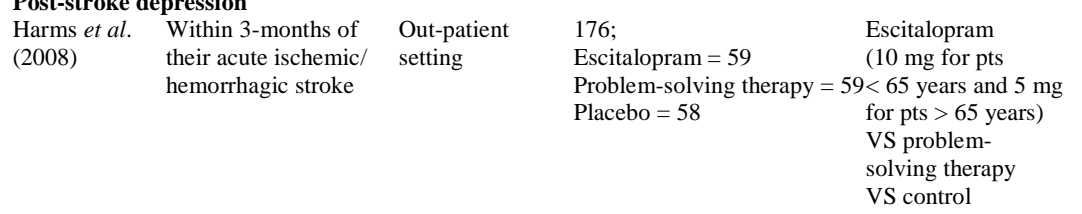

Vascular dementia

\begin{tabular}{|c|c|c|c|c|}
\hline $\begin{array}{l}\text { Goodwin and } \\
\text { Devanand } \\
\text { (2008) }\end{array}$ & $\begin{array}{l}\text { Patients with } \\
\text { CADASIL syndrome }\end{array}$ & $\begin{array}{l}\text { Out-patient } \\
\text { setting }\end{array}$ & $\begin{array}{l}168 ; \\
\text { Donepezil }=86 \\
\text { Placebo }=82\end{array}$ & $\begin{array}{l}\text { Donepezil } 10 \mathrm{mg} \\
\text { daily Vs placebo } \\
\text { for } 18 \text { weeks }\end{array}$ \\
\hline
\end{tabular}
(2008)

Placebo $=82$

Glucose levels were significantly lower in the aggressive-treatment group throughout protocol treatment $\left(7.4 \mathrm{Vs} 10.5 \mathrm{mmol} \mathrm{L}^{-1}\right.$ [133 Vs $\left.\left.190 \mathrm{mg} \mathrm{dL}^{-1}\right], \mathrm{p}<0.001\right)$. Hypoglycemia $<3.3 \mathrm{mmol} \mathrm{L}^{-1}\left(<60 \mathrm{mg} \mathrm{dL}^{-1}\right)$ occurred only in the aggressive-treatment group (11 patients, 35\%). The clinical outcomes (modified Rankin scale, Barthel index, NIHSS and stroke specific quality of life Scale) were similar between the treatment groups.

In the 10 days observation period, 15 of 30 patients in the intervention Vs 27 of 30 patients in the conventionally treated group developed an infection $(\mathrm{p}<0.05)$. Mean interval until the diagnosis of infection was 5.1 days in the intervention group and 3.3 days in the control group $(\mathrm{p}<0.05)$. Clinical outcome (modified rankin scale) favored patients with prophylactic therapy $(\mathrm{p}=0.01)$. On intention-to-treat analysis (79 patients), the infection rate at day 11 in the moxifloxacin was $15.4 \%$ compared to $32.5 \%$ in the placebo group $(\mathrm{p}=0.114)$. On per-protocol-analysis $(\mathrm{n}=66)$, moxifloxacin significantly reduced infection rate from $41.9 \%$ to $17.1 \%(\mathrm{p}=0.032)$.

Patients in the placebo group had more depression than individuals who received escitalopram (11 major and 2 minor cases of depression [22.4\%] Vs 3 major and 2 minor cases of depression [8.5\%], $(\mathrm{p}<0.001)$ and individuals who received problem-solving therapy ( 5 major and 2 minor cases of epression [11.9\%], $(p<0.001)$. On an intentionto-treat basis, escitalopram was superior to placebo $(23.1 \%$ Vs $34.5 \%$; $p=0.007)$, while problem-solving therapy was no different than placebo $(30.5 \%$ Vs $34.5 \%$; $\mathrm{p}=0.51)$.

There was no significant difference between donepezil $(\mathrm{n}=84)$ and placebo $(\mathrm{n}=77)$ in the primary endpoint (V-ADAS-cog) $(\mathrm{p}=0.96)$. There was a significant treatment effect favoring donepezil on the secondary outcomes: TMT B time $(\mathrm{p}=0.02)$, TMT A time $(\mathrm{p}=0.015)$ and EXIT-25 $(\mathrm{p}=0.02)$. 
Am. Med. J. 1 (1): 8-22, 2010

Table 1: Continued

Subarachnoid Hemorrhage (SAH) and stroke

Rabadi et al. Within 4 days of Acute

(2008) fisher grade III SAH hospitalization

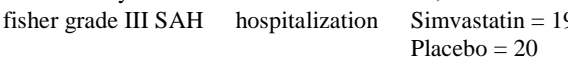

413;

Robinson et al. Within $56 \mathrm{~h}$ to Neurosurgical 413

(2008) 14 days of their SAH

Clazosentan $=317$

$\left(1 \mathrm{mg} \mathrm{h}^{-1}=108\right.$,

$5 \mathrm{mg} \mathrm{h}^{-1}=111$,

$15 \mathrm{mg} \mathrm{h}^{-1}=98$ )

Placebo $=96$

$\begin{array}{llll}\begin{array}{l}\text { Chou } \text { et al. } \\ \text { (2008) }\end{array} & \begin{array}{l}\text { Within 4 days of } \\ \text { fisher Grade III } \\ \text { (and IV) SAH }\end{array} & \begin{array}{l}\text { Acute } \\ \text { hospitalization }\end{array} & \begin{array}{l}170 ; \\ \text { TBA }=85 \\ \text { Control }=85\end{array}\end{array}$

Surgery and stroke

Macdonald et al. Within 28 days of Neurosurgical 278;

(2008) SAH on head CT or centers $\quad$ NST $=140$

lumbar puncture
$\mathrm{EVT}=138$
Simvastatin

$80 \mathrm{mg} \mathrm{day}^{-1}$

or placebo

Clazosentan

IV in 1,5 and

$15 \mathrm{mg} \mathrm{h}^{-1} \mathrm{Vs}$

placebo

Prophylactic

Transluminal

balloon

angioplasty (TBA)

under general

anesthesia

VS control
Angiographically-confirmed vasospasm

occurred in $8 / 20$ placebo and $5 / 19$ simvastatintreated subjects. Vasospasm-related ischemic infarcts developed in $5 / 20$ placebo and 2/19 simvastatin-treated subjects. Death was $3 / 20$ in the placebo and $0 / 19$ in the simvastatin group.

Moderate or severe vasospasm was reduced in a dose-dependent fashion from $66 \%$ in the placebo to $23 \%$ in the $15 \mathrm{mg} \mathrm{h}^{-1}$ clazosentan group ( $\mathrm{p}<0.0001)$. On post hoc analysis for cerebral infarcts and delayed ischemic neurological deficit due to vasospasm on central review a trend favored clazosentan (37, 28 and $29 \%$ for the 1,5 and $15 \mathrm{mg} \mathrm{h}^{-1}$ groups versus $39 \%$ in the placebo group) was seen

pTBA had an absolute risk reduction of $5.9 \%$ and a relative risk reduction of $10.4 \%$ unfavorable outcome $(\mathrm{p}=0.54)$. The incidence of vasospasm related cerebral ischemia was lower in the pTBA group $(\mathrm{p}=0.30)$ and fewer patients required therapeutic angioplasty to treat vasospasm $(\mathrm{p}=0.03) .4$ patients had a procedure-related vessel perforation, of which 3 patients died. This was a negative trial as fewer patients developed vasospasm after treatment with pTBA.

Of the patients allocated to EVT 83 of 138 $(60.1 \%)$ were independent compared to 78 of $140(56.1 \%)$ allocated NST. In patients with internal carotid and posterior communicating artery aneurysms EVT36 of $50(72.0 \%)$ was superior to 26 of $5052.0 \%$ ) allocated (NST $(\mathrm{p}<0.05)$. In patients with middle cerebral artery aneurysms NST 13 of $15(86.7 \%)$ was superior to EVT 10 of $22(45.5 \%)(\mathrm{p}<0.05)$. The frequency of epilepsy was $0.7 \%$ in the EVT compared to $12.9 \%$ in the NST group $(\mathrm{p}<0.001)$

\section{CONCLUSION}

The following conclusions can be drawn from the studies summarized here: (1) extending the time-window for administration of alteplase from 3-4.5 h after stroke onset improved clinical outcome; (2) treatment of hypertension in the elderly does reduce rate of stroke, cardiac failure and death from stroke; (3) fixed dose unmonitored idraparinux was as effective as warfarin in primary stroke prevention, however, was associated with increase bleeding risk; (4) neither DP-b99 nor allopurinol proved to be an effective neuroprotectant; (5) antiplatelet agent Sarpogrelate was as effective as aspirin in secondary stroke prevention, hence a new anti-platelet to the growing list of effective anti-platelet agents; (6) aggressive management of hyperglycaemia does not improve clinical outcome; (7) prophylactic antibiotic use after an acute stroke reduced the rate of secondary infection with improved clinical outcome; (8) prophylactic anti-depressant use lowers the incidence of depression for 12 months post-stroke; (9) though donepezil improved measures of executive function it did not translate into clinical improvement; (10) both statins and clazosentan in reduced subarachnoid hemorrhage induced vasospasm and delayed cerebral infarction, and finally (11) non-pharmacotherapies such as clips were safe to use in patient's with subarachnoid hemorrhage in the internal carotid and posterior communicating artery aneurysm while middle cerebral artery aneurysm benefited from coils.

\section{REFERENCES}

Abciximab Emergent Stroke Treatment Trial (ABESTT) Investigators, 2005. Emergency administration of abciximab for treatment of patients with acute ischemic stroke: Results of a randomized phase 2 trial. Stroke, 36: 880-890. PMID: 15731473

Abciximab in Ischemic Stroke Investigators, 2000. Abciximab in acute ischemic stroke: A randomized, double-blind, placebo-controlled, dose-escalation study. Stroke, 31: 601-9. PMID: 10700492 
Adams Jr., H.P., M.B. Effron, J. Torner, A. Dávalos and J. Frayne et al., 2008. AbESTT-II Investigators. Emergency administration of abciximab for treatment of patients with acute ischemic stroke: Results of an international phase iii trial: Abciximab in Emergency Treatment of Stroke Trial (AbESTTII). Stroke, 39: 87-99. PMID: 18032739

Alexandrov, A.V., C.A. Molina, J.C. Grotta, Z. Garami and S.R. Ford et al., 2004. CLOTBUST Investigators. Ultrasound-enhanced systemic thrombolysis for acute ischemic stroke. N. Eng. J. Med., 351: 2170-2208. PMID: 15548777

Alexandrov, A.V., R. Mikulik, M. Ribo, V.K. Sharma and A.Y. Lao et al., 2008. A pilot randomized clinical safety study of sonothrombolysis augmentation with ultrasound-activated perflutrenlipid microspheres for acute ischemic stroke. Stroke, 39: 1464-1509. PMID: 18356546

Amadeus Investigators, M.G. Bousser, J. Bouthier, H.R. Büller, A.T. Cohen and H. Crijns et al., 2008. Comparison of idraparinux with vitamin $\mathrm{k}$ antagonists for prevention of thromboembolism in patients with atrial fibrillation: A randomised, open-label, non-inferiority trial. Lancet, 371: 315-321. PMID: 18294998

Baird, T.A., M.W. Parsons, T. Phanh, K.S. Butcher and P.M. Desmond et al., 2003. Persistent poststroke hyperglycemia is independently associated with infarct expansion and worse clinical outcome. Stroke, 34: 2208-2214. PMID: 12893952

Beckett, N.S., R. Peters, A.E. Fletcher, J.A. Staessen and L. Liu et al., 2008. HYVET Study Group. Treatment of hypertension in patients 80 years of age or older. N. Eng. J. Med., 358: 1887-1898. PMID: 18378519

Bruno, A., T.A. Kent, B.M. Coull, R.R. Shankar and C. Saha et al., 2008. Treatment of Hyperglycemia in Ischemic Stroke (THIS): A randomized pilot trial. Stroke, 39: 384-409. PMID: 18096840

Chitravas, N., H.M. Dewey, M.B. Nicol, D.L. Harding and D.C. Pearce et al., 2007. Is prestroke use of angiotensin-converting enzyme inhibitors associated with better outcome? Neurology, 68: 1687-1693. PMID: 17502550

Chou, S.H., E.E. Smith, N. Badjatia, R.G. Nogueira and J.R. Sims et al., 2008. A randomized double-blind, placebo-controlled pilot study of simvastatin in aneurysmal subarachnoid hemorrhage. Stroke, 39: 2891-2703. PMID: 18658043

Christou, I., R.A. Felberg, A.M. Demchuk, W.S. Burgin and M. Malkoff et al., 2002. Intravenous tissue plasminogen activator and flow improvement in acute ischemic stroke patients with internal carotid artery occlusion. J. Neuroimag., 12: 119-123. PMID: 11977905
Davis, S.M., G.A. Donnan, M.W. Parsons, C. Levi and K.S. Butcher et al., 2008. EPITHET investigators. Effects of alteplase beyond 3 hafter stroke in the echoplanar imaging thrombolytic evaluation trial (epithet): A placebo-controlled randomised trial. Lancet Neurol., 7: 299-309. PMID: 18296121

Dawson, J., T.Q. Quinn and M.R. Walters 2007. Xanthine oxidase inhibition-A new paradigm in management of cardiovascular risk. Curr. Med. Chem., 14: 1879-1886.

Dichgans, M., H.S. Markus, S. Salloway, A. Verkkoniemi and M. Moline et al., 2008. Donepezil in patients with subcortical vascular cognitive impairment: A randomised double-blind trial in CADASIL. Lancet. Neurol., 7: 310-8. PMID: 18296124

Diener, H.C., D. Schneider, Y. Lampl, N.M. Bornstein and A. Kozak et al., 2008. DP-B99, A membraneactivated metal ion chelator, as neuroprotective therapy in ischemic stroke. Stroke, 39: 1774-1808. PMID: 18403736

Eggers, J., I.R. König, B. Koch, G. Händler and G. Seidel, 2008. Sonothrombolysis with transcranial color-coded sonography and recombinant tissue-type plasminogen activator in acute middle cerebral artery main stem occlusion: Results from a randomized study. Stroke, 39: 1470-1505. PMID: 18340100

Goodwin, R.D. and D.P. Devanand, 2008. Stroke depression and functional health outcomes among adults in the community. J. Geriatric Psychiatry Neurol., 21: 41-46. PMID: 18287169

Gray, C.S., A.J. Hildreth, P.A. Sandercock, J.E. O'Connell and D.E. Johnston et al., 2007. GIST trialists collaboration. Glucose-potassium-insulin infusions in the management of post-stroke hyperglycaemia: The UK Glucose Insulin in Stroke Trial (GISTUK). Lancet Neurol., 6: 397-406. PMID: 17434094

Hacke, W., M. Kaste, E. Bluhmki, M. Brozman and A. Dávalos et al., 2008. ECASS Investigators. Thrombolysis with alteplase 3-4.5 h after acute ischemic stroke. N. Eng. J. Med., 359: 1317-29. PMID: 18815396

Harms, H., K. Prass, C. Meisel, J. Klehmet and W. Rogge et al., 2008. Preventive antibacterial therapy in acute ischemic stroke: A randomized controlled trial. PLOS One. 3: e2158. PMID: 18478129

Krakovsky, M., M. Polyak, I. Angel and A. Kozak, 2001. A Novel Membrane Targeted Compound Active Against Global And Focal Ischemia. In: Physiological Imaging of the Brain with PET, Gjedde A.S.H., G.M. Knudsen and O.B. Paulson (Eds.). Academic Press, New York, pp: 347-352. 
Macdonald, R.L., N.F. Kassell, S. Mayer, D. Ruefenacht and P. Schmiedek et al., 2008. CONSCIOUS-1 Investigators. Clazosentan to overcome neurological ischemia and infarction occurring after subarachnoid hemorrhage (CONSCIOUS-1): Randomized, double-blind, placebo-controlled phase 2 dose-finding trial. Stroke, 39: 3015-3021. PMID: 18688013

Muir, S.W., C. Harrow, J. Dawson, K.R. Lees and C.J. Weir et al., 2008. Allopurinol use yields potentially beneficial effects on inflammatory indices in those with recent ischemic stroke: A randomized, double-blind, placebo-controlled trial. Stroke, 39: 3303-3307. PMID: 18845806

Muizelaar, J.P., M. Zwienenberg, N.A. Rudisill and S.T. Hecht, 1999. The prophylactic use of transluminal balloon angioplasty in patients with fisher grade 3 subarachnoid hemorrhage: A pilot study. J. Neurosurg., 91: 51-58. PMID: 10389880

Pancioli, A.M., J. Broderick, T. Brott, T. Tomsick and J. Khoury et al., 2008. For the CLEAR Trial Investigators. The Combined Approach to Lysis Utilizing Eptifibatide and rt-PA in Acute Ischemic Stroke: The CLEAR Stroke Trial. Stroke, 39: 32683276. PMID: 18772447

Rabadi, M.H., F.M. Rabadi, L. Edelstein and M. Peterson, 2008. Cognitively impaired stroke patients do benefit from admission to an acute rehabilitation unit. Arch. Phys. Med. Rehabil., 89: 441-8. PMID: 18295621

Robinson, R.G., R.E. Jorge, D.J. Moser, L. Acion and A. Solodkin et al., 2008. Escitalopram and problem-solving therapy for prevention of poststroke depression: A randomized controlled trial. J. Am. Med. Assoc., 299: 2391-2400. PMID: 18505948

Ryttlefors, M., P. Enblad, R.S. Kerr and A.J. Molyneux, 2008. International subarachnoid aneurysm trial of neurosurgical clipping versus endovascular coiling: Subgroup analysis of 278 elderly patients. Stroke. 39: 2720-2726. PMID: 18669898

Sacco, R.L., H.C. Diener, S. Yusuf, D. Cotton and S. Ounpuu et al., 2008. The PROFESS Study Group. Aspirin and extended-release dipyridamole versus clopidogrel for recurrent stroke. N. Eng. J. Med., 359: 1238-1251. PMID: 18753638
Schwarz, S., F. Al-Shajlawi, C. Sick, S. Meairs and M.G. Hennerici, 2008. Effects of prophylactic antibiotic therapy with mezlocillin plus sulbactam on the incidence and height of fever after severe acute ischemic stroke: The Mannheim Infection in Stroke Study (MISS). Stroke, 39: 1220-1227. PMID: 18309164

Shinohara, Y., K. Nishimaru, T. Sawada, A. Terashi and S. Handa et al., 2008. Sarpogrelate-aspirin comparative clinical study for efficacy and safety in secondary prevention of cerebral infarction (SACCESS): A randomized, double-blind, aspirincontrolled trial. Stroke, 39: 1827-1833. PMID: 18388340

Topol, E.J., 2001. GUSTOV Investigators. Reperfusion therapy for acute myocardial infarction with fibrinolytic therapy or combination reduced fibrinolytic therapy and platelet glycoprotein iib/iiia inhibition: The GUSTOV randomized trial. Lancet., 357: 1905-1914. PMID: 11425410

Weir, C.J., S.W. Muir, M.R. Walters and K.R. Lees, 2003. Serum urate as an independent predictor of poor outcome and vascular events after acute stroke. Stroke, 34: 1951-1957. PMID: 12843346

Yusuf, S., H.C. Diener, R.L. Sacco, D. Cotton and S. Ounpuu et al., 2008. The PROFESS Study Group. Telmisartan to prevent recurrent stroke and cardiovascular events. N. Eng. J. Med., 359: 1225-1237. PMID: 18753639

Zwienenberg-Lee, M., J. Hartman, N. Rudisill, L.K. Madden and K. Smith et al., 2008. Balloon Prophylaxis for Aneurysmal Vasospasm (BPAV) Study Group. Effect of prophylactic transluminal balloon angioplasty on cerebral vasospasm and outcome in patients with fisher grade III subarachnoid hemorrhage: Results of a phase II multicenter, randomized, clinical trial. Stroke, 39: 1759-1765. PMID: 18420953 